Original article

\title{
The Age, Creatinine and Ejection fraction (ACEF_Score as Predictor of Acute Kidney Injury in Patients Undergoing Primary versus Elective Percutaneous Coronary Intervention
}

\author{
Tarek Ahmed Naguib, Mohammad Mustafa Al-Daydammony, Alaa Elsayed Salama, Mohammed Abd \\ Elkawy Eid* \\ Cardiology department, Faculty of medicine, Zagazig University, Egypt
}

*Corresponding Author:

Mohammed Abd Elkawy Eid cardiology resident.

Mohamedeid2019@yahoo.com

$\begin{array}{ll}\text { Submit Date } & 2019-03-14 \\ \text { Revise Date } & 2019-05-04 \\ \text { Accept Date } & 2019-05-09\end{array}$

\begin{abstract}
Background_Age, creatinine and ejection fraction (ACEF) score has been established as a predictor of clinical outcomes in patients undergoing primary Percutaneous Coronary Intervention. Its utility in patients undergoing elective percutaneous coronary intervention is yet unexplored.

AIM OF WORK_This study aims to investigate the risk factors associated with Acute Kidney Injury development in patients with ST segment Elevation undergoing primary PCI or with Coronary Artery Disease undergoing elective PCI.We investigates the applicability of ACEF score on patients undergoing elective PCI

Patients and Methods_ calculating ACEF score for 80 patients divided into two groups: group I will include 40 patients for primary PCI and group II will include 40 patients for elective PCI with fixation of type (meglumine- ioxitalamate) and amount $(\leq 300 \mathrm{ml})$ of the contrast used .

Results_ 8 patients from 80 had AKI; 4 patients from each group .There was no significant difference between both groups regarding smoking, history of diabetes mellitus, hypertension, dyslipidemia and family history of IHD in primary PCI group versus elective PCI group.

Conclusion_ A fully pre-procedural risk prediction model would be useful to facilitate precautionary measures for patients at a high risk of Contrast Induced Nephropathy. ACEF risk score incorporate only 3 variables, which may make it more acceptable for clinical use, because of its simplicity.ACEF score can be used to predict AKI in patients undergoing primary PCI as well as elective PCI.
\end{abstract}

Keywords: ACEF score, acute kidney injury, percutaneous coronary intervention, acute myocardial infarction, chronic kidney disease, ischemic heart disease.

\section{INTRODUCTION}

ontrast-induced nephropathy (CIN) occurs
more frequently after primary
percutaneous coronary intervention (PPCI) in
patients with ST-segment elevation myocardial
infarction (STEMI). CIN incidence has been
reported to be as high as 28\%. Furthermore,
CIN is strongly associated with late renal and
cardiovascular adverse events [1]. Acute kidney injury is common among hospitalized patients. It affects $3-7 \%$ of patients admitted to the hospital and approximately $25-30 \%$ of patients in the intensive care unit Acute kidney injury is defined as any of the following: increase in Serum Creatinine (SCr) by $\geq 0.3 \mathrm{mg} / \mathrm{dl}(\geq 26.5$ $\mu \mathrm{mol} / \mathrm{l})$ within 48 hours; OR increase in SCr to $\geq 1.5$ times baseline, which is known or presumed to have occurred within prior 7 days; 
OR Urine volume $<0.5 \mathrm{ml} / \mathrm{kg} / \mathrm{h}$ for 6 hour [2].Primary Percutaneous Coronary Intervention (PCI) is defined as angioplasty and/or stenting without prior or concomitant fibrinolytic therapy, and is the preferred therapeutic option when it can be performed by an experienced team[3].Elective PCI is defined as all procedures that were not urgent/emergent, that is, PCI not within $24 \mathrm{hrs}$. Of MI, and excluding patients with shock and hemodynamic instability. Elective PCI can be performed safely without intra-aortic balloon pump (IABP) or cardiopulmonary support (CPS) in most circumstances. Most patients can be safely discharged from the hospital within $24 \mathrm{~h}$ after an uncomplicated elective PCI[4]. The advanced age, depressed EF and increased serum creatinine are independent predictors of AKI development after PCI. The individual patient risk can be assessed by calculating the ACEF score, which is based on clinical information. Calculation of ACEF according to (Ranucci at al. (2009)): age/EF (\%) +1 is added if creatinine was $\geq 2[5]$.

\section{AIM OF WORK}

This study aims to investigate the risk factors associated with Acute Kidney Injury development in patients with ST segment Elevation undergoing primary PCI or with Coronary Artery Disease undergoing elective PCI.We investigates the applicability of ACEF score on patients undergoing elective PCI

\section{PATIENTS AND METHODS}

Written informed consent was obtained from all participants and the study was approved by the research ethical committee of Faculty of Medicine, Zagazig University. The work has been carried out in accordance with The Code of Ethics of the World Medical Association (Declaration of Helsinki) for studies involving humans

Study population_ This study is a prospective observation study conducted from January 2017 to October 2018 and included 80 patients from the National Heart Institute and cardiology department of Zigzag University undergoing primary or elective percutaneous coronary intervention divided into two groups first group include 40 patients undergoing primary percutaneous coronary intervention and the second group include 40 patients undergoing elective percutaneous coronary intervention.

Methods_History taking including (comorbidity-drug intake).Clinical examination. Kidney function test (creatinine) daily. Measurement of serum creatinine on admission, 6 hours after the procedure, every day for the following 3 days, and at discharge from the CCU. Wall motion abnormalities and left ventricular ejection fraction would be assessed with echocardiography in all subjects using a GE Vivid 9 Ultrasound Machine (Echo Pac; GE Vingmed, Horten, Norway) before PCI. Group I patients will undergo primary PCI and group II patients will undergo elective PCI with fixed type (meglumine- ioxitalamate) and amount ( $\leq 300 \mathrm{ml})$ of contrast material (7)Calculation of ACEF according to (Ranucci at al. (2009)): age $/ \mathrm{EF}(\%)+1$ is added if creatinine was $\geq 2$.

Inclusion criteria_All patients who will present with typical cardiac chest pain suspecting ACS not responsive to nitrates, with or without ECG changes consistent with myocardial ischemia or acute myocardial infarction (STEMI) planned for primary percutaneous coronary intervention and patients with Coronary Artery Disease planned for elective percutaneous coronary intervention.

Exclusion criteria_1.Patients on chronic peritoneal or hemodialysis treatment

2. Patients who have allergy to contrast material 3. Patients who receive contrast in last week

ACEF Score and Analysis_ The ACEF score was calculated according to the following formula: $\mathrm{ACEF}=$ age/left ventricular ejection fraction +1 is added if creatinine was $\geq 2$.It is score to predict AKI after PCI. Low risk ACEF score <1.027, Moderate Risk ACEF score 1.027-1.277, High Risk ACEF score $>1.277$.

(5).

Study endpoints_the study end point was the occurrence of CIN in both groups with same percentage to confirm the applicability of ACEF score on elective PCI, defined as either a greater than $25 \%$ increase of serum creatinine 
or an absolute increase in serum creatinine of $0.5 \mathrm{mg} / \mathrm{dl}$ from baseline value, at 48 hours following the exposure to procedure.

Statistical analysis_the collected data were analyzed by computer using Statistical Package of Social Services version 24 (SPSS) (Armonk, NY ,USA ,IBM. corp.), Data were represented in tables and graphs, Continuous Quantitative variables e.g. age were expressed as the mean \pm $\mathrm{SD}$, and categorical qualitative variables were expressed as absolute frequencies (number) \& relative frequencies (percentage). Suitable statistical tests of significance were used after checking data for normality. The results were considered statistically significant when the significant probability was less than 0.05 ( $\mathrm{P}<$ $0.05)$. P-value $<0.001$ was considered highly statistically significant (HS), and P-value $\geq 0.05$ was considered statistically insignificant (NS).

\section{RESULTS}

The current study was done to investigate the risk of developing acute kidney injury in patients undergoing primary and elective percutaneous coronary intervention, it included 80 patients (63 male and 17 female), the study subjects were allocated into 2 groups according to percutaneous coronary intervention into primary PCI and elective PCI, mean of age among the studied primary PCI is $53.8 \pm 10.08$ years old, with a range from 31 to 78 years old and $87.5 \%$ of them are males. While age of the studied Elective PCI was $56.85 \pm 10.26$ years old, with a range from 31 to 80 years old and $70 \%$ of them are males, there was no statistically significant difference between both groups regarding age and sex distribution, as illustrated in table (1) and figure (1). There was no significant difference between both groups regarding smoking and history of diabetes mellitus, hypertension, dyslipidemia and family history of IHD with percentage $(70 \%, 47 \%, 37.5 \%, 7.5 \%$ \&zero $\%)$ respectively in primary PCI group versus (52.5\%, $52.5 \%, 55 \%, 12.5 \%$ \& $7.5 \%)$ respectively in elective PCI group as illustrated in table(2) and figure (2).Ejection fraction was statistically higher in elective PCI group than primary PCI with range(32-60) in primary PCI and range (30-75) in elective PCI , 10\% of the studied patients in both groups developed contrast induced nephropathy with no significant difference as illustrated in Table (3). Total ACEF was statistically higher in primary PCI group than elective PCI, in $2.5 \%$ of primary PCI serum creatinine level increased more than $2 \mathrm{mg} / \mathrm{dl}$ with no statistical difference between both groups as illustrated in Table (4). There was significant positive correlation between age of patient and Total ACEF and age/EF and serum creatinine level before PCI and after PCI, there was significant negative correlation between Ejection fraction and total $\mathrm{ACEF}$ and age/EF( $\mathrm{r}=-.476,-.476$ and $\mathrm{P}$-value < $0.05)$ respectively among the studied elective PCI group as in table (5).Regarding serum creatinine level, there was significant strong positive correlation between creatinine level before PCI and after PCI, the higher creatinine level before, the higher creatinine level after PCI, also there was positive correlation between creatinine level at $6 \mathrm{hr}$. after PCI and creatinine levels at 1 st and 2 nd day among the studied elective PCI group as in table (5). There was significant positive correlation between age of patient and Total ACEF and age/EF, there was significant negative correlation between Ejection fraction and total $\mathrm{ACEF}$ and age/EF(r $=-.603,-.566$ and $\mathrm{P}$-value $<0.05)$ respectively among primary PCI groups illustrated in table (6). Regarding serum creatinine level, there was significant strong positive correlation between creatinine level before PCI and after PCI, the higher creatinine level before, the higher creatinine level after PCI $(p=0.000)$ as illustrated in table (6).there was High level and moderate level of ACEF score were statistically high in old age in primary PCI group as in Table (7) .There was no statistically significant difference between levels of ACEF regarding Sex, risk factors in primary PCI group as in Table (7). There was High level and moderate level of ACEF score were statistically high in old age, There was no statistically significant difference between levels of ACEF regarding Sex, risk factors in elective PCI group as in Table (8). 
Table (1): Socio-demographic characteristics of the studied groups

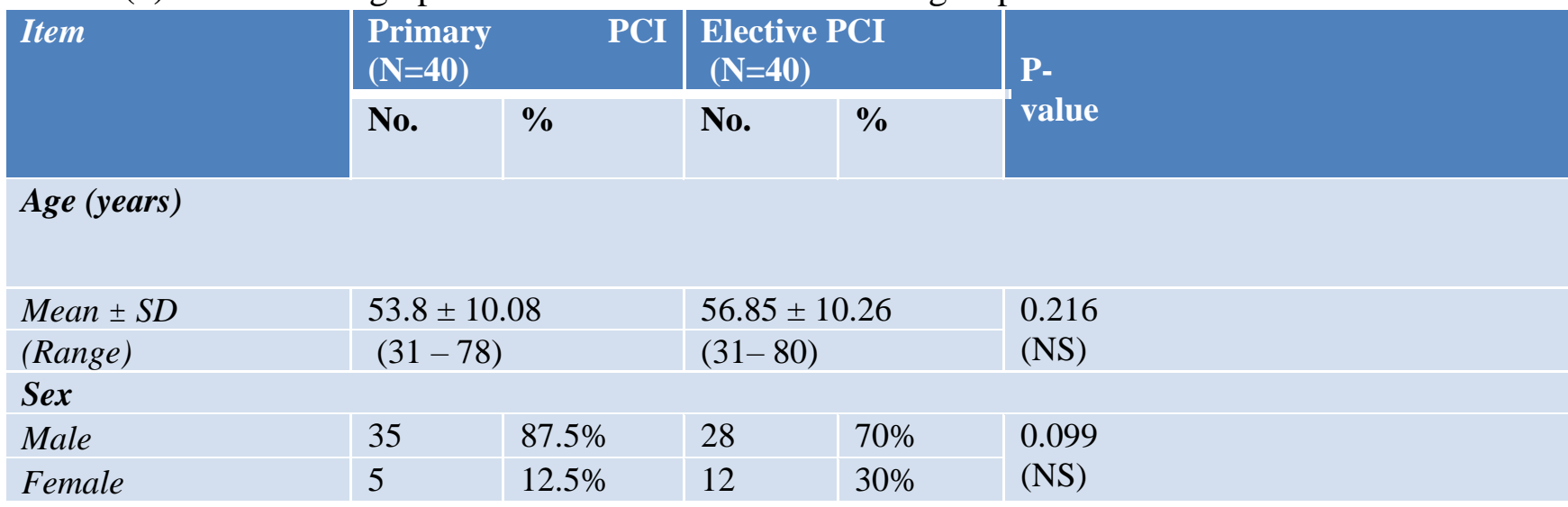

Table (2): History of smoking and comorbidities among the studied groups.

\begin{tabular}{|c|c|c|c|c|c|}
\hline \multirow[t]{2}{*}{ Variable } & \multicolumn{2}{|c|}{$\begin{array}{l}\text { Primary } \\
(\mathrm{N}=40)\end{array}$} & \multicolumn{2}{|c|}{$\begin{array}{l}\text { Elective PCI } \\
(\mathrm{N}=40)\end{array}$} & \multirow[t]{2}{*}{ P-valu } \\
\hline & No. & $\%$ & No. & $\%$ & \\
\hline \multicolumn{6}{|l|}{ Smoking } \\
\hline No & 12 & 30.0 & 19 & 47.5 & \multirow{2}{*}{$\begin{array}{l}0.168 \\
(\mathrm{NS})\end{array}$} \\
\hline Yes & 28 & 70.0 & 21 & 52.5 & \\
\hline \multicolumn{6}{|l|}{ iabetes } \\
\hline No & 21 & 52.5 & 19 & 47.5 & \multirow{2}{*}{$\begin{array}{l}0.832 \\
\text { (NS) }\end{array}$} \\
\hline Yes & 19 & 47.5 & 21 & 52.5 & \\
\hline \multicolumn{6}{|c|}{ ypertension } \\
\hline No & 25 & 62.5 & 18 & 45.0 & \multirow{2}{*}{$\begin{array}{l}0.178 \\
(\mathrm{NS})\end{array}$} \\
\hline Yes & 15 & 37.5 & 22 & 55.0 & \\
\hline \multicolumn{6}{|c|}{ Dyslipidemia } \\
\hline No & 37 & 92.5 & 35 & 87.5 & \multirow{2}{*}{$\begin{array}{l}0.712 \\
(\mathrm{NS})\end{array}$} \\
\hline Yes & 3 & 7.5 & 5 & 12.5 & \\
\hline \multicolumn{6}{|c|}{ Family history of ischemic heart disease } \\
\hline No & 40 & 100.0 & 37 & 92.5 & \multirow{2}{*}{$\begin{array}{l}0.241 \\
\text { (NS) }\end{array}$} \\
\hline Yes & 0 & 0.0 & 3 & 7.5 & \\
\hline
\end{tabular}

Table (3): Contrast induced nephropathy and Ejection fraction after PCI among the studied groups

\begin{tabular}{|c|c|c|c|c|c|}
\hline \multirow[t]{2}{*}{ Item } & \multicolumn{2}{|c|}{$\begin{array}{l}\text { Primary } \\
(\mathrm{N}=40)\end{array}$} & \multicolumn{2}{|c|}{$\begin{array}{l}\text { Elective PCI } \\
(\mathrm{N}=40)\end{array}$} & \multirow[b]{2}{*}{$\begin{array}{l}\text { P- } \\
\text { value }\end{array}$} \\
\hline & No. & $\%$ & No. & $\%$ & \\
\hline \multicolumn{6}{|c|}{ Ejection fraction } \\
\hline Mean \pm SD & \multicolumn{2}{|c|}{$45.83 \pm 7.11$} & \multicolumn{2}{|c|}{$58.78 \pm 10.13$} & \multirow{2}{*}{$\begin{array}{l}0.000^{*} \\
\text { (HS) }\end{array}$} \\
\hline (Range) & \multicolumn{2}{|c|}{$(32-60)$} & \multicolumn{2}{|c|}{$(30-75)$} & \\
\hline \multicolumn{6}{|l|}{ CIN } \\
\hline No & 36 & $90 \%$ & 36 & $90 \%$ & \multirow{2}{*}{$\begin{array}{l}1.000 \\
(\mathrm{NS})\end{array}$} \\
\hline Yes & 4 & $10 \%$ & 4 & $10 \%$ & \\
\hline
\end{tabular}


Table (4): The ACEF Score before PCI among the studied groups

\begin{tabular}{|c|c|c|c|c|c|}
\hline \multirow[t]{2}{*}{ Item } & \multicolumn{2}{|c|}{ Primary PCI $(\mathrm{N}=40)$} & \multicolumn{2}{|c|}{$\begin{array}{l}\text { Elective PCI } \\
(\mathrm{N}=40)\end{array}$} & \multirow[b]{2}{*}{$\begin{array}{l}\text { P- } \\
\text { value }\end{array}$} \\
\hline & No. & $\%$ & No. & $\%$ & \\
\hline \multicolumn{6}{|l|}{ Age/EF } \\
\hline $\begin{array}{l}\text { Mean } \pm \text { SD } \\
\text { (Range) }\end{array}$ & \multicolumn{2}{|c|}{$1.20 \pm 0.29$} & \multicolumn{2}{|c|}{$0.997 \pm 0.27$} & $\begin{array}{l}0.000^{*} \\
\text { (HS) }\end{array}$ \\
\hline \multicolumn{6}{|c|}{ Total ACEF } \\
\hline $\begin{array}{l}\text { Mean } \pm \text { SD } \\
\text { (Range) }\end{array}$ & \multicolumn{2}{|c|}{$1.22 \pm 0.37$} & \multicolumn{2}{|c|}{$0.997 \pm 0.273$} & \multirow[t]{2}{*}{$\begin{array}{l}0.000 * \\
(\mathrm{HS})\end{array}$} \\
\hline \multicolumn{5}{|c|}{ If serum creatinine $>2$} & \\
\hline $\begin{array}{l}\text { No } \\
\text { Yes }\end{array}$ & $\begin{array}{l}39 \\
1\end{array}$ & $\begin{array}{l}97.5 \\
2.5\end{array}$ & $\begin{array}{l}40 \\
0\end{array}$ & $\begin{array}{l}100.0 \\
0.0\end{array}$ & $\begin{array}{l}1.000 \\
(\mathrm{NS})\end{array}$ \\
\hline
\end{tabular}

Table (5): correlation matrix between ACEF score and serum creatinine among the studied elective PCI group.

\begin{tabular}{|c|c|c|c|c|c|c|c|c|}
\hline \multicolumn{2}{|c|}{ Correlation coefficient } & TOTAL & AGE/EF & EF & $\begin{array}{l}\text { S.CRE } \\
2 \text { DAY }\end{array}$ & $\begin{array}{l}\text { S.CRE } \\
1 \text { DAY }\end{array}$ & $\begin{array}{l}\text { S.CRE } \\
6 \text { HRS }\end{array}$ & $\begin{array}{l}\text { S.CRE } \\
\text { BEFOR } \\
\text { E }\end{array}$ \\
\hline \multirow[t]{2}{*}{ AGE/EF } & (r) & $1.000^{* *}$ & & & & & & \\
\hline & P-value & 0.000 & & & & & & \\
\hline \multirow[t]{2}{*}{$\mathbf{E F}$} & $(\mathbf{r})$ & $-.476^{* *}$ & $-.476^{* *}$ & & & & & \\
\hline & P-value & .002 & .002 & & & & & \\
\hline \multirow{2}{*}{$\begin{array}{l}\text { S.CRE } \\
\text { at } 2 \text { DAY }\end{array}$} & $(\mathbf{r})$ & $.478^{* *}$ & $.478^{* *}$ & -.160 & & & & \\
\hline & P-value & .002 & .002 & .323 & & & & \\
\hline \multirow{2}{*}{$\begin{array}{l}\text { S.CRE at } \\
1 \text { DAY }\end{array}$} & $(\mathbf{r})$ & $.395^{*}$ & $.395^{*}$ & -.084 & $.850^{* *}$ & & & \\
\hline & P-value & .012 & .012 & .606 & .000 & & & \\
\hline \multirow{2}{*}{$\begin{array}{l}\text { S.CRE } \\
\text { at } 6 \text { HRS }\end{array}$} & $(\mathbf{r})$ & .271 & .271 & .058 & $.465^{* *}$ & $.423^{* *}$ & & \\
\hline & P-value & .091 & .091 & .722 & .003 & .006 & & \\
\hline \multirow{2}{*}{$\begin{array}{l}\text { S.CRE } \\
\text { BEFORE }\end{array}$} & $(\mathbf{r})$ & .281 & .281 & .044 & $.454^{* *}$ & $.407^{* *}$ & $.995^{* *}$ & \\
\hline & P-value & .079 & .079 & .790 & .003 & .009 & .000 & \\
\hline \multirow[t]{2}{*}{ age } & $(\mathbf{r})$ & $.616^{* *}$ & $.616^{* *}$ & $.325^{*}$ & $.446^{* *}$ & $.460^{* *}$ & $.452^{* *}$ & $.451^{* *}$ \\
\hline & P-value & .000 & .000 & .041 & .004 & .003 & .003 & .003 \\
\hline
\end{tabular}


Table (6): correlation matrix between ACEF score and serum creatinine among the studied primary PCI group.

\begin{tabular}{|c|c|c|c|c|c|c|c|c|}
\hline \multicolumn{2}{|c|}{ Correlation coefficient } & TOTAL & AGE/EF & $\mathrm{EF}$ & $\begin{array}{l}\text { S.CRE } 2 \\
\text { DAY }\end{array}$ & $\begin{array}{l}\text { S.CRE } 1 \\
\text { DAY }\end{array}$ & $\begin{array}{l}\text { S.CRE6 } \\
\text { HRS }\end{array}$ & $\begin{array}{l}\text { S.CRE } \\
\text { BEFORE }\end{array}$ \\
\hline \multirow[t]{2}{*}{ AGE/EF } & (r) & $.968^{* *}$ & & & & & & \\
\hline & p-value & .000 & & & & & & \\
\hline \multirow[t]{2}{*}{ EF } & (r) & $-.603^{* *}$ & $-.566^{* *}$ & & & & & \\
\hline & p-value & .000 & .000 & & & & & \\
\hline \multirow{2}{*}{$\begin{array}{l}\text { S.CRE } \\
\text { at } 2 \text { DAY }\end{array}$} & (r) & .298 & .239 & -.040 & & & & \\
\hline & p-value & .062 & .138 & .806 & & & & \\
\hline \multirow{2}{*}{$\begin{array}{l}\text { S.CRE } \\
\text { at } 1 \text { DAY }\end{array}$} & (r) & .258 & .196 & -.088 & $.929^{* *}$ & & & \\
\hline & p-value & .107 & .225 & .588 & .000 & & & \\
\hline \multirow{2}{*}{$\begin{array}{l}\text { S.CRE } \\
\text { at } 6 \text { HRS }\end{array}$} & (r) & .179 & .113 & .119 & $.801^{* *}$ & $.818^{* * *}$ & & \\
\hline & p-value & .269 & .486 & .466 & .000 & .000 & & \\
\hline \multirow{2}{*}{$\begin{array}{l}\text { S.CRE } \\
\text { BEFORE }\end{array}$} & (r) & .196 & .131 & .101 & $.794^{* *}$ & $.811^{* * *}$ & $.998^{* *}$ & \\
\hline & p-value & .225 & .420 & .536 & .000 & .000 & .000 & \\
\hline \multirow[t]{2}{*}{ Age } & (r) & $.709^{* *}$ & $.772^{* * *}$ & .013 & .262 & .148 & .236 & .252 \\
\hline & p-value & .000 & .000 & .938 & .103 & .361 & .142 & .117 \\
\hline
\end{tabular}

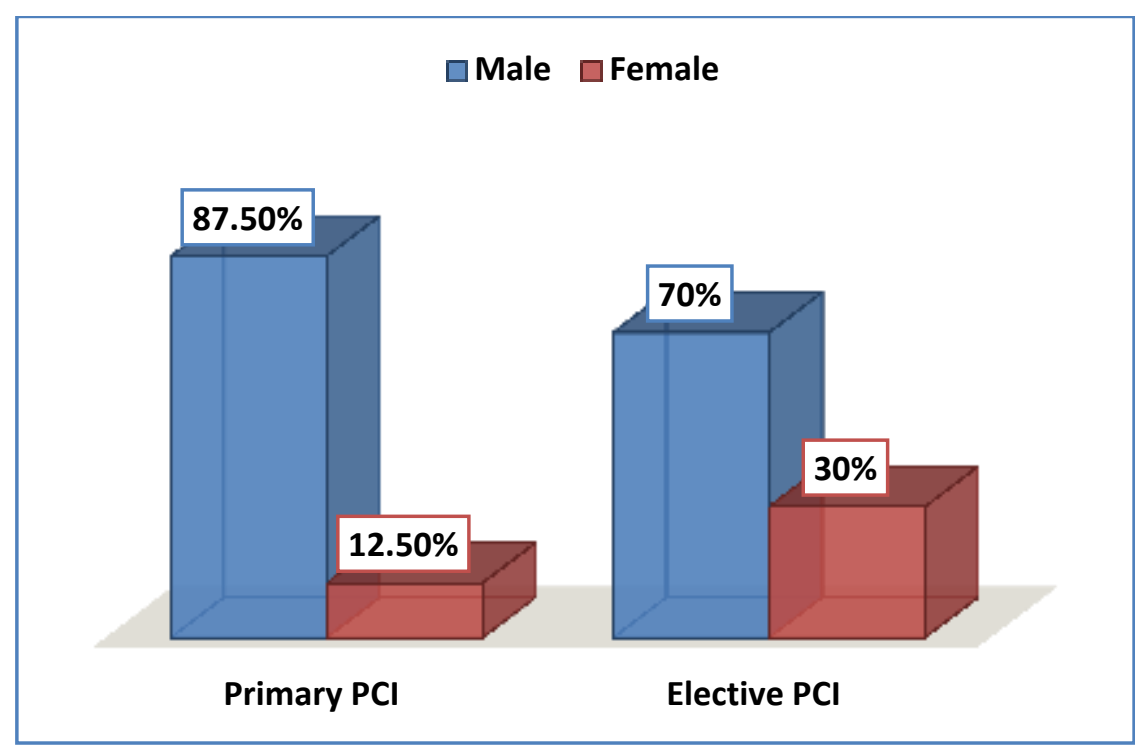

Figure 1.Bar chart for comparison of sex among the studied groups

\section{DISCUSSION}

Contrast-induced nephropathy (CIN) is an acute kidney injury that follows intravascular administration of radio-opaque contrast media $(\mathrm{CM})$ in susceptible individuals. It remains responsible for a third of all hospital-acquired acute kidney injury (AKI) and affects between $1 \%$ and $2 \%$ of the general population [8].In primary PCI group, Our study showed that there was highly significant relation between

1- age and level of ACEF score
Our study showed that there was positive correlation between the age and ACEF score level when the mean age was $42.33 \pm$ 7.76(31 - 57) the ACEF score was low $(<1.027)$, when the mean age was $45.88 \pm 7.71$ $(43-71)$ the ACEF score was moderate (from 1.027 to 1.277 ) and when the mean age was $56.86 \pm 7.93(45-78)$ the ACEF score was high $(>1.277)$ with $\mathrm{p}$ value (.0000) and this was concordant with (Ando et al., 2013) [2], who studied 481 patients that referred to the 
Coronary Care Unit(CCU) of the University Hospital of Messina from January 2008 to June2011 for primary PCI in the course of STEMI, in being the advanced age is independent predictors of AKI development after primary PCI for STEMI as $\mathrm{p}$ value was $(<.001)$.

2- EF and total ACEF

Our study showed that there was negative correlation between Ejection fraction and total ACEF EF ( $\mathrm{r}=-.603,-.566)$ respectively and this was concordant with (Ando et al., 2013) [2], who studied 481 patients that referred to the Coronary Care Unit (CCU) of the University Hospital of Messina from January 2008 to June2011 for primary PCI in the course of STEMI, in being EF is independent predictors of AKI development after primary PCI for STEMI with $\mathrm{p}$ value (.001).

3- Serum creatinine and total ACEF

Our study showed that there was significant strong positive correlation between creatine level before PCI and after PCI, the higher creatinine level before, the higher creatinine level after PCI $(\mathrm{p}=0.000)$ and this was concordant with (Ando et al., 2013) [2], who studied 481 patients that referred to the Coronary Care Unit(CCU) of the University Hospital of Messina from January 2008 to June2011 for primary PCI in the course of STEMI , in being serum creatinine is independent predictors of AKI development after primary PCI for STEMI with $\mathrm{p}$ value (<.001) . In primary PCI group, Our study showed that there was no significant relation between ACEF score and the other risk factors in the form of DM with $\mathrm{p}$ value (0.661), hypertension with $\mathrm{p}$ value $(0.159)$,dyslipidemia with $\mathrm{p}$ value $(0.555)$, smoking with $\mathrm{p}$ value (0.079) sex with $p$ value $(0.314)$ and this was concordant with (Andoet al., 2013)(2) that show there was no significance with ACEF and other risk factors like DM with p value (0.02), Hypertension with p value $(0.01)$, dyslipidemia with $p$ value (1.0), smoking with $p$ value $(0.02)$ sex with $\mathrm{p}$ value $(0.64)$.
In elective PCI group, Our study showed that there was highly significant relation between :

1- age and level of ACEF score

Our study showed that there was positive correlation between the age and ACEF score level when the mean age was52.43 \pm 9.02 $(31-67)$ the ACEF score was low $(<1.027)$, when the mean age was $63.08 \pm$ 9.23(47 - 80)the ACEF score was moderate (from 1.027 to 1.277 )and when the mean age was $62 \pm 9.05(52-73)$ the ACEF score was high $(>1.277)$ with $\mathrm{p}$ value (.004) and this was [9],concordant with (Wykrzykowska et al., 2011) who studied 1208 who represented to CCU with Acute Coronary Syndrome, in being the advanced age is independent predictors of AKI development after elective PCI as $\mathrm{p}$ value is $(<.001)$.

2- EF and total ACEF

Our study showed that there was negative correlation between Ejection fraction and total $\operatorname{ACEFEF}((\mathrm{r}=-.476$ and -.476) respectively and this was concordant with (Wykrzykowska et al., 2011) [9] , who studied 1208 who represented to CCU with Acute Coronary Syndrome, in being the advanced age is independent predictors of AKI development after elective PCI as p value is $(<.001)$.

3- Serum creatinine and total ACEF

Our study showed that there was significant strong positive correlation between creatine level before PCI and after PCI, the higher creatinine level before, the higher creatinine level after PCI $(p=0.000)$, also there was positive correlation between creatinine level at $6 \mathrm{hr}$. after PCI and creatinine levels at 1st and 2nd day and this was concordant with,( Dziewierzet al., 2017), [9] 1425 patient with ACS admitted to 29 community hospitals without on-site invasive facilities in this region of Poland . Data were collected during two separate enrollment periods: from February 2005 to March 2005 and from December 2005 to January 2006,in being serum creatinine is independent predictors of AKI development after elective with $\mathrm{p}$ value $(<.001)$. 
4- Our study showed that there was no significant relation between ACEF score and smoking as $p$ value was (.727) and hypertension as $\mathrm{p}$ value was (.844) which was disconcordant with (Wykrzykowska et al., 2011) [9] , who studied 1208 who represented to CCU with Acute Coronary Syndrome, that reported smoking and hypertension had significant relation with ACEF score with $p$ value (<.001) for both and this may be for the large number of patients taken in the study .

In elective PCI group, Our study showed that there was no significant relation between ACEF score and the other risk factors in the form of DM with $p$ value (.600) ,dyslipidemia with $\mathrm{p}$ value (.509) and sex with $\mathrm{p}$ value (.588) and this was concordant with (Wykrzykowska et al., 2011) [9], who studied 1208 who represented to CCU with Acute Coronary Syndrome,that showed that there was no significant relation between ACEF score and the other risk factor DM, Dyslipidemia, sex with $p$ value $(0.008,0.019,0.009)$ respectively .

In comparison with the two groups elective and primary PCI, Our study showed that there was no significant difference between both groups regarding smoking and history of diabetes mellitus, hypertension, dyslipidemia and family history of IHD and this was concordant with (Wykrzykowska et al., 2011) [9] , who studied 1208 who represented to CCU with Acute Coronary Syndrome that showed that ACEF score may be a simple way to stratify risk of events in patients treated with percutaneous coronary intervention with respect to mortality and risk of myocardial infarction and this proved that ACEF score can be used in elective PCI like primary PCI .

\section{CONCLUSION}

A fully pre-procedural risk prediction model would be useful to facilitate precautionary measures for patients at a high risk of CIN. The ACEF include LVEF. However, ACEF risk score incorporate only 3 variables, which may make it more acceptable for clinical use, because of its simplicity.ACEF score can be used to predict acute kidney injury in patients undergoing primary PCI as well as elective PCI.

\section{Limitations of the study}

1. Relatively small sample size of this study.

2. Different operators with variable skills

3. Although all our patients effectively underwent contrast media exposure. we cannot exclude the possibility that other factors, such as hemodynamic instability, might have contributed, at least in part, to renal impairment and influenced the clinical outcome of our patients. Indeed, in addition to contrast agent volume, other factors reflecting cardiocirculatory impairment, such as anterior AMI, longer time to reperfusion were independently related to the development of renal dysfunction.

\section{RECOMMENDATION}

This study recommends risk stratification before treating patients with myocardial revascularization as identification and intervention for patients undergoing PCI who are at high risk of CIN are crucial to improve clinical outcomes. This study recommends starting hydration before and after PCI, as well as an optimized choice of contrast medium, for the prevention of CIN. On the other hand, renal function should always be monitored in patients with AMI after catheterization, even in patients with GFR $>60 \mathrm{~mL} / \mathrm{min} / 1.73 \mathrm{~m}$.

\section{Declaration of interest}

The authors report no conflicts of interest. The authors alone are responsible for the content and writing of the paper.

\section{Funding information}

None declared

\section{REFERENCES}

(1) Kurnik, B. R., Allgren, R. L., Genter, F. C., Solomon, R. J., Bates, E. R., \& Weisberg, L. S. (1998). Prospective study of atrial natriuretic peptide for the prevention of radiocontrastinduced nephropathy. AJKD; 31(4): 674-680.

(2) Andò, G., Morabito, G., de Gregorio, C., Trio, O., Saporito, F., \& Oreto, G. (2013). Age, glomerular filtration rate, ejection fraction, and the AGEF score predict contrast-induced nephropathy in patients with acute myocardial infarction undergoing primary percutaneous coronary intervention. Catheterization and Cardiovascular Interventions; 82(6): 878-885. 
(3) Spaulding, C., Henry, P., Teiger, E., Beatt, K., Bramucci, E., Carrié, D., ... \& Varenne, O. (2006). Sirolimus-eluting versus uncoated stents in acute myocardial infarction. NEJM, 355(11), 1093-1104.

(4) Peterson, E. D., Dai, D., DeLong, E. R., Brennan, J. M., Singh, M., Rao, S. V., ... \& Krone, R. J. (2010). Contemporary mortality risk prediction for percutaneous coronary intervention: results from 588,398 procedures in the National Cardiovascular Data Registry. JACC, 55(18), 1923-1932.

(5) Ranucci M, Castelvecchio S, Menicanti L, Frigiola A, Pelissero G. Risk of assessing mortality risk in elective cardiac operations: age, creatinine, ejection fraction, and the law of parsimony. Circulation 2009;119:3053-61.

(6) Stacul, F., van der Molen, A. J., Reimer, P., Webb, J. A., Thomsen, H. S., Morcos, S. K., \& Heinz-Peer, G. (2011). Contrast induced nephropathy: updated ESUR contrast media safety committee guidelines. European radiology; 21(12): 2527-2541.

(7) Brown, J. R., Robb, J. F., Block, C. A., Schoolwerth, A. C., Kaplan, A. V., O'connor, G. T., \& Malenka, D. J. (2010). Does safe dosing of iodinated contrast prevent contrast-induced acute kidney injury?. Circulation: Cardiovascular Interventions, CIRCINTERVENTIONS-109.

(8) Nash, K., Hafeez, A., \& Hou, S. (2002). Hospital-acquired renal insufficiency. AJKD; 39(5): 930-936.

(9) Wykrzykowska, J. J., Garg, S., Onuma, Y., de Vries, T., Goedhart, D., Morel, M. A., \& Klauss, V. (2011). Value of age, creatinine, and ejection fraction (ACEF score) in assessing risk in patients undergoing percutaneous coronary interventions in the 'All-Comers' LEADERS trial. Circulation: Cardiovascular Interventions, CIRCINTERVENTIONS-110.

(10) Singhal, G., Pathak, V., \& Kumar, M. (2017). Incidence of contrast induced acute kidney injury in patients undergoing percutaneous coronary intervention in North Indian population. JICC; 7(4): 143-148.

(11) Dziewierz, A., Siudak, Z., Rakowski, T., Zasada, W., Krzanowska, K., \& Dudek, D. (2017). The ACEF (age, creatinine, ejection fraction) score predicts ischemic and bleeding outcomes of patients with acute coronary syndromes treated conservatively. Advances in Interventional Cardiology; 13(2): 160.

To Cite This Article: Naguib TA, Al-Daydammony MM, Salama AE, Eid MA.The Age, Creatinine and Ejection fraction $\left(\mathrm{ACEF}_{-}\right.$Score as Predictor of Acute Kidney Injury in Patients Undergoing Primary versus Elective Percutaneous Coronary Intervention.ZUMJ 2019;25(5);773-781. DOi: 10.21608/zumj.2019.10231.10870. 